\title{
A SNaPshot assay for the rapid and simple detection of four common hotspot codon mutations in the PIK3CA gene Carolyn D Hurst ${ }^{1}$, Tahlita CM Zuiverloon ${ }^{2}$, Christian Hafner ${ }^{3}$, Ellen C Zwarthoff ${ }^{2}$ and Margaret A Knowles*1
}

\author{
Address: ${ }^{1}$ Cancer Research UK Clinical Centre, Leeds Institute of Molecular Medicine, St James's University Hospital, Leeds, UK, ${ }^{2}$ Department of \\ Pathology, Josephine Nefkens Institute, Erasmus MC, Rotterdam, the Netherlands and ${ }^{3}$ Department of Dermatology, University of Regensburg, \\ 93042 Regensburg, Germany \\ Email: Carolyn D Hurst - c.hurst@leeds.ac.uk; Tahlita CM Zuiverloon - t.zuiverloon@erasmusmc.nl; \\ Christian Hafner - christian.hafner@klinik.uni-regensburg.de; Ellen C Zwarthoff - e.zwarthoff@erasmusmc.nl; \\ Margaret A Knowles* - m.a.knowles@leeds.ac.uk \\ * Corresponding author
}

Published: 29 April 2009

BMC Research Notes 2009, 2:66 doi:10.1 186/1756-0500-2-66

This article is available from: http://www.biomedcentral.com//756-0500/2/66

(C) 2009 Knowles et al; licensee BioMed Central Ltd.

This is an Open Access article distributed under the terms of the Creative Commons Attribution License (http://creativecommons.org/licenses/by/2.0), which permits unrestricted use, distribution, and reproduction in any medium, provided the original work is properly cited.
Received: 3 October 2008

Accepted: 29 April 2009

\begin{abstract}
Background: Activating mutations in the PIK3CA gene have been identified in a variety of human malignancies and are commonly detected in hotspot codons located in the helical and kinase domains in exons 9 and 20. Existing methodologies for the detection of PIK3CA mutations are timeconsuming and/or expensive. In the present study we describe the first application of a PIK3CA $\mathrm{SNaPshot}$ assay to the screening of frequent mutations in these exons.

Findings: A SNaPshot assay for the simultaneous detection of four frequent PIK3CA hotspot mutations (E542K, E545G, E545K and HI047R) has been developed and evaluated. The assay combines multiplex PCR amplification with a multiplex primer extension assay to allow targeted detection of all four mutations in one reaction. The method was tested using samples that had previously been analysed for mutations by high-resolution melting analysis and sequencing. All mutations detected were concordant and no false positive results were obtained. Sensitivity tests showed that the SNaPshot assay could detect mutant DNA when it represents $5-10 \%$ of the total DNA present. The application of the method to the analysis of DNAs extracted from formalinfixed paraffin-embedded samples was also demonstrated.
\end{abstract}

Conclusion: The SNaPshot assay described here offers a fast, sensitive, inexpensive and specific approach to the analysis of frequent PIK3CA mutations in both fresh and archival patient samples.

\section{Background}

The phosphatidylinositol 3-kinase (PI3K) pathway plays an important role in many cellular processes including cell proliferation, adhesion, survival and motility. Dysregulation of this pathway has been observed in many types of human malignancy and has commonly been associated with genetic alterations in components of the pathway (reviewed in [1]). Such genetic alterations include activating mutations in the PIK3CA gene encoding the $\mathrm{p} 110 \alpha$ subunit of class IA PI3K.

Somatic mutations of PIK3CA have now been reported in several types of human cancer [2-13]. Although mutations have been detected throughout the PIK3CA gene, com- 
mon mutational hotspots occur in the helical (exon 9) and kinase (exon 20) domains with E542K, E545K and H1047R being most frequent. Recently, mutations of PIK3CA were also detected in epidermal nevi (EN) and seborrheic keratoses (SK), two benign skin lesions [14]. All mutations detected in EN samples were of the E545G type whereas SK displayed E542K, E545K and H1047R mutations.

PCR-based screening methods (e.g. single strand conformation polymorphism analysis, high resolution melting analysis, ARMS/Scorpion assays) and direct sequencing of PCR products have typically been applied to the identification of PIK3CA mutations $[5,13,15,16]$. However, with large numbers of samples, these approaches are time consuming and/or expensive. As specific inhibitors for PIK3CA become available it will be essential to be able to screen patient samples rapidly. Primer extension (SNaPshot) assays have been developed for several genes with common mutations, e.g. FGFR3 and BRCA1/2 [17,18]. The SNaPshot method offers a specific, sensitive, inexpensive and rapid alternative to screening for mutations and subsequent confirmation by sequencing. Here we describe a SNaPshot assay for the simultaneous detection of the PIK3CA mutations, E542K, E545G, E545K and H1047R.

\section{Methods}

\section{Samples and DNA extraction}

Sixteen bladder tumour-derived cell lines (5637, 253J, 639V, 647V, 97-21, 97-24, 97-29, BFTC909, CAL29, HT1197, HT1376, J82, JO'N, TCC-SUP, VMCUB1, VMCUB3), 175 fresh-frozen bladder tumour tissue samples and 5 formalin-fixed paraffin-embedded seborrheic keratosis samples were used. All DNAs were extracted using a QIAmp DNA kit.

\section{Multiplex PCR primers and SNaPshot probes}

Multiplex PCR primers and SNaPshot probes were selected using a web-based oligonucleotide check tool http://depts.washington.edu/bakerpg/primertemp/ primermelttemp.html so that they had matching melting temperatures of approximately $65^{\circ} \mathrm{C}$. Primer sequences were analysed for secondary structures, complementarity and specificity. Primers were selected for amplification of exon 9 (ex9-Fw 5'-AGTAACAGACTAGCTAGAGA-3'; ex9-
Rv 5'-ATTTTAGCACTTACCTGTGAC-3') and exon 20 (ex20-Fw 5'-GACCCTAGCCTTAGATAAAAC-3'; ex20-Rv 5'-GTGGAAGATCCAATCCATTT-3'), with the amplicons covering hotspot codons 542, 545 and 1047. SNaPshot probes for detection of E542K, E545G, E545K and $\mathrm{H} 1047 \mathrm{R}$ mutations were designed to anneal on the sense strand immediately adjacent to the mutation site (Table 1). Each probe was synthesised with a different length of poly(dT) tail to allow separation of SNaPshot products on the basis of size (Table 1).

\section{Multiplex PCR amplification}

Multiplex PCR was performed in a volume of $15 \mu \mathrm{l}$ containing $1 \times$ PCR buffer, $1.5 \mathrm{mM} \mathrm{MgCl}_{2}, 0.17 \mathrm{mM}$ dNTPs, $0.7 \mu \mathrm{M}$ of each primer, $5 \%$ glycerol, 1 unit GoTaq DNA polymerase and $20 \mathrm{ng}$ of template DNA. Thermal cycler conditions were: $95^{\circ} \mathrm{C}$ for $5 \mathrm{~min}, 35$ cycles of $95^{\circ} \mathrm{C}$ for 45 $\mathrm{sec}, 60^{\circ} \mathrm{C}$ for $45 \mathrm{sec}, 72^{\circ} \mathrm{C}$ for $45 \mathrm{sec}$ and finally $10 \mathrm{~min}$ at $72^{\circ} \mathrm{C}$. The number of cycles was increased to 45 for the analysis of DNAs extracted from paraffin-embedded material. Multiplex PCR products were checked for quality and yield by running $3 \mu \mathrm{l}$ in $2 \%$ agarose-TBE gels. The remaining PCR products were treated with 3 units of shrimp alkaline phosphatase and 2 units of exonuclease I to remove excess deoxyribonucleotide triphosphates (dNTPs) and primers, respectively.

\section{SNaPshot analysis}

SNaPshot analysis was performed using an Applied Biosystems SNaPshot Multiplex Kit. Reactions were performed in a volume of $9 \mu \mathrm{l}$ containing $2.5 \mu \mathrm{l}$ of SNaPshot Ready Multiplex Ready Reaction Mix, $1 \times$ BigDye sequencing buffer, $1 \mu$ l of probe mix (see Table 1 for probe concentrations) and $1 \mu \mathrm{l}$ of shrimp alkaline phosphatase/ exonuclease-treated multiplex PCR product. Extension reactions were performed in a thermal cycler and consisted of 35 cycles of denaturation at $95^{\circ} \mathrm{C}$ for $10 \mathrm{sec}$ and annealing/extension at $58.5^{\circ} \mathrm{C}$ for $40 \mathrm{sec}$. Labelled extension products were treated with shrimp alkaline phosphatase ( 1 unit per sample) then diluted 1 in $10.1 \mu \mathrm{l}$ of the diluted extension product was mixed with $9.8 \mu \mathrm{l}$ of $\mathrm{HiDi}^{\mathrm{TM}}$ formamide and $0.2 \mu \mathrm{l}$ of Genescan-120LIZ size standard. Products were denatured at $95^{\circ} \mathrm{C}$ for 5 minutes then separated using an ABI PRISM 3100 Genetic Analyzer with a $36 \mathrm{~cm}$ length capillary and POP- ${ }^{\mathrm{TM}}$ polymer. Analysis was performed using GeneMapper 3.7 Software.

Table I: SNaPshot probes for the detection of PIK3CA mutations.

\begin{tabular}{|c|c|c|c|c|}
\hline Probe & Sequence $\left(5^{\prime}->3 '\right)$ & Size (bp) & Mutation & $\begin{array}{c}\text { Concentration } \\
\text { in probe mix }(\mu \mathrm{M})\end{array}$ \\
\hline E542K & $\mathrm{T}_{(19)}$ TACACGAGATCCTCTCTCT & 38 & $G->A$ & 0.8 \\
\hline E545G & $\mathrm{T}_{(29)}$ TCCTCTCTCTGAAATCACTG & 49 & $A->G$ & 2.3 \\
\hline E545K & $\mathrm{T}_{(34)}^{(27)}$ ATCCTCTCTCTGAAATCACT & 54 & $\mathrm{G}->\mathrm{A}$ & 1.5 \\
\hline HI047R & $\mathrm{T}_{(46)}^{(34)}$ TGAAACAAATGAATGATGCAC & 67 & $A->G$ & 1.5 \\
\hline
\end{tabular}




\section{Sensitivity of the SNaPshot assay}

Mixtures of bladder tumour DNAs heterozygous for PIK3CA mutations and normal DNA were prepared to test the sensitivity of the SNaPshot assay. $20 \mathrm{ng}$ of template DNA containing mutant DNA at final percentages of $100 \%, 25 \%, 10 \%, 5 \%$ or $1 \%$ was used in SNaPshot analysis.

\section{Results and discussion}

The first step of the SNaPshot assay described here involved the design and optimisation of a multiplex PCR reaction for the simultaneous amplification of DNA fragments from exons 9 and 20. Relatively small PCR amplification product sizes (139 bp for exon 9 and 109 bp for exon 20) were chosen so that the assay could be applied to the analysis of partially degraded DNA samples such as those obtained from formalin-fixed paraffin-embedded samples. PCR primers were initially tested in single-product reactions prior to being used in multiplex reactions. Similar quantities of both products were observed in multiplex PCR reactions.

The primer extension (SNaPshot) assay utilises an Applied Biosystems SNaPshot Multiplex Kit that contains a reaction mix of four differentially fluorescently labelled ddNTPs, allowing the interrogation of each base at a mutation site. When used in combination with the sizespecific PIK3CA SNaPshot probes (Table 1), it was possible to screen simultaneously for E542K, E545G, E545K and $\mathrm{H} 1047 \mathrm{R}$ mutations. Initially, extension reactions were performed using equal concentrations of the probes. Subsequently, the concentration of each probe was adjusted to give more comparable peak heights (Table 1).

To evaluate the performance of the SNaPshot assay we performed a blind screen of 16 bladder tumor-derived cell line and 175 fresh-frozen primary bladder tumor DNAs that had previously been analysed for PIK3CA mutations in exons 9 and 20 by high-resolution melting analysis using the LightScanner system and direct sequencing (Platt et al. manuscript in preparation). SNaPshot detected heterozygous mutations in 7 cell lines (E542K n $=1$ [VMCUBI]; E545G n = 1 [253J]; E545K n = 4 [HT1197; BFTC909; VMCUB3; TCC-SUP]; H1047R n = 1 [CAL29]) and 37 tumors, and results were 100\% concordant with the data obtained by Platt et al. A representative example of each of the four common codon mutations detected in the cell lines is shown in Figure 1(A-E). Peaks are colourcoded by the Genemapper software according to the dyelabel on the incorporated ddNTP. Genotype scoring is manual and is based on the peak colour and position relative to a set of internal size standards. Mutations in each codon were easily identified on the basis of peak size and colour. Slight shifts in the molecular weights of mutant alleles were observed due to mobility differences in the fluorophores used to detect each of the bases. However, probes were sufficiently spaced such that these mobility differences did not impair interpretation of the resulting electropherograms.

We also applied the method to a panel of five DNAs extracted from formalin-fixed paraffin-embedded seborrheic keratoses. When analysing samples of this nature it was observed that the quality of SNaPshot results obtained was invariably linked to the intensity of the multiplex PCR products. To obtain sufficient multiplex PCR product for SNaPshot analysis, the number of PCR amplification cycles was therefore increased to 45 for these samples. Screening revealed an E542K mutation in one of the DNAs (Figure 1F) whilst all other samples were found to be wildtype, confirming results obtained previously by direct sequencing [19].

Finally, we assessed the sensitivity of the SNaPshot assay by mixing heterozygous mutant DNA from low grade/ stage bladder tumors (that are commonly diploid or neardiploid) with normal DNA in varying proportions. We were able to detect mutations E542K, E545K and H1047R when mutant DNA represented $5-10 \%$ of the total input DNA. Figure 2 shows representative examples of results obtained for codons E542K and E545K. As mutant DNAs used in these experiments were heterozygous, the observed sensitivity results equate to being able to detect one mutant allele in a background of $39(5 \%)$ or 19 $(10 \%)$ wildtype alleles. This level of detection is comparable to that reported for the FGFR3 SNaPshot assay of van Oers et al. [17]. We were also able to achieve a 5\% level of detection for codon $\mathrm{E} 545 \mathrm{~K}$ when mutant DNAs from two triploid bladder tumor cell lines (TCC-SUP and BFTC909) were used (data not shown). Calling the presence of lowlevel mutations is more difficult and in these cases more than one individual should perform scoring and the assay should be repeated to confirm that the mutations do not represent artefacts.

It is perhaps surprising that we did not uncover extra mutations to those detected by the LightScanner and direct sequencing approach. Board et al. [15] reported that conventional sequencing was unable to detect the presence of H1047R and E542K mutations when present at $<50 \%$ and $<30 \%$ of the total mixture, respectively. On this basis, the SNaPshot assay should be more sensitive than the LightScanner and direct sequencing confirmation approach. The high concordance of results most likely reflects the fact that the DNAs analysed in our study were extracted from samples consisting of $>80 \%$ tumor cells.

The SNaPshot assay described in the present study represents a relatively inexpensive approach to the detection of PIK3CA mutations. The cost of the SNaPshot Multiplex 
A

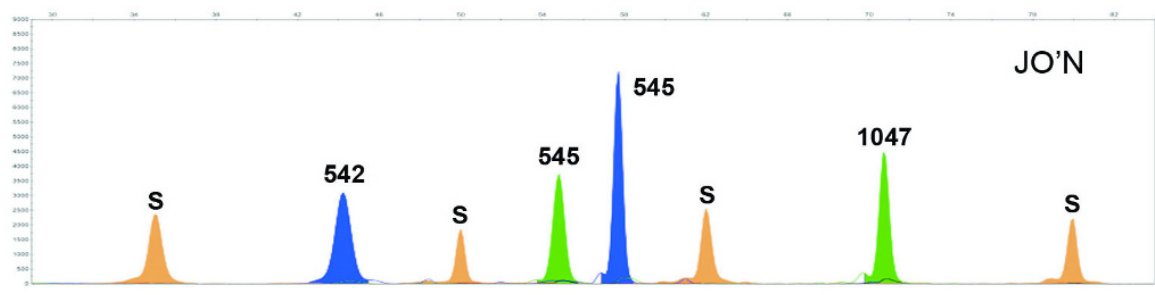

B

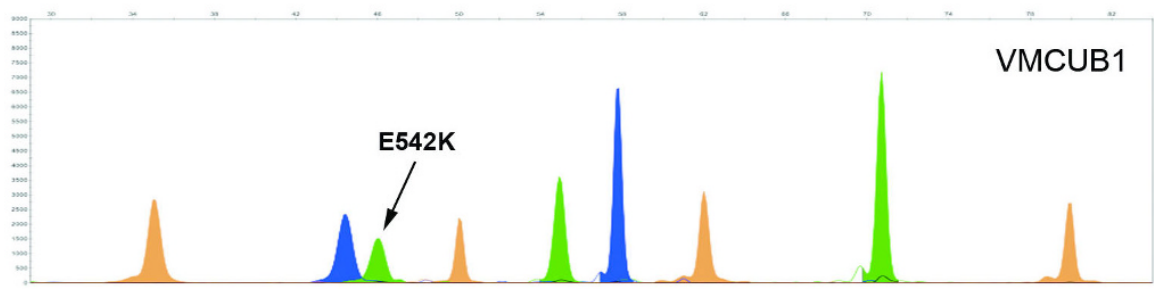

C

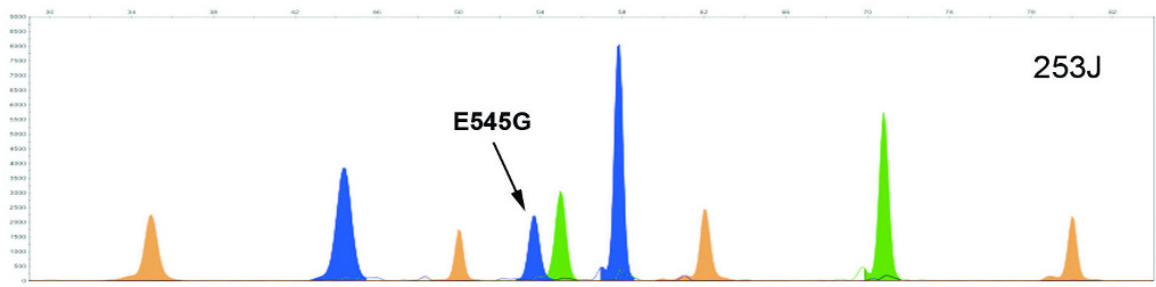

D

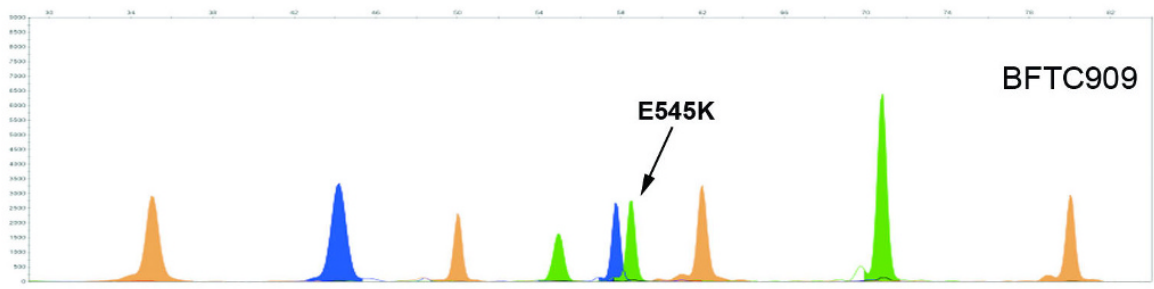

E

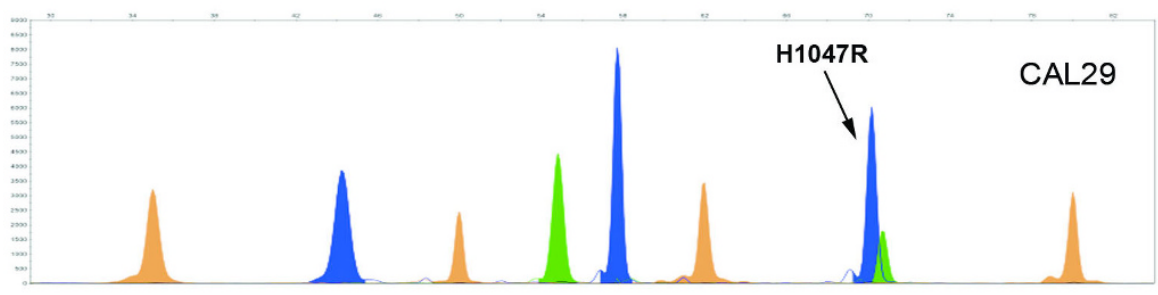

$\mathbf{F}$

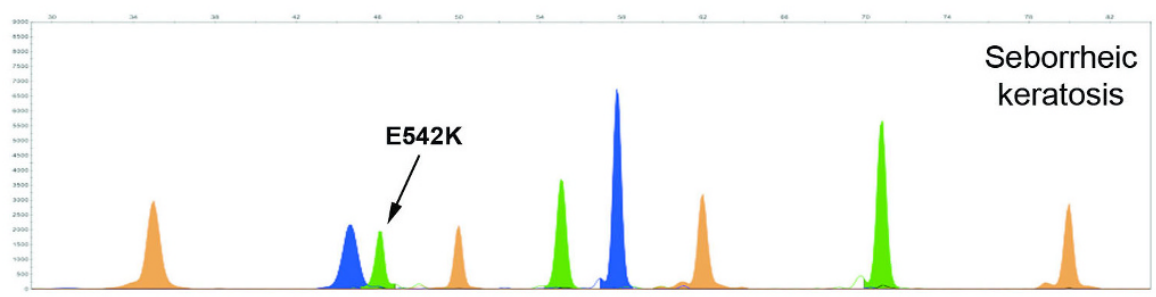

Figure I

SNaPshot detection of four common hotspot mutations in the PIK3CA gene. (A-E) SNaPshot results obtained from the analysis of bladder tumor-derived cell line DNAs illustrating (A) wildtype, (B) E542K, (C) E545G, (D) E545K and (E) HI047R electropherogram patterns. (F) SNaPshot detection of an E542K codon mutation in DNA extracted from a formalinfixed paraffin embedded seborrheic keratosis sample. Bases are represented by the following colours: $A=$ green; $C=$ black; $G$ = blue; $T$ = red. Orange peaks $(S)$ represent the internal Genescan- I20LIZ size standards. All DNAs were extracted using a QIAmp DNA kit. 
A
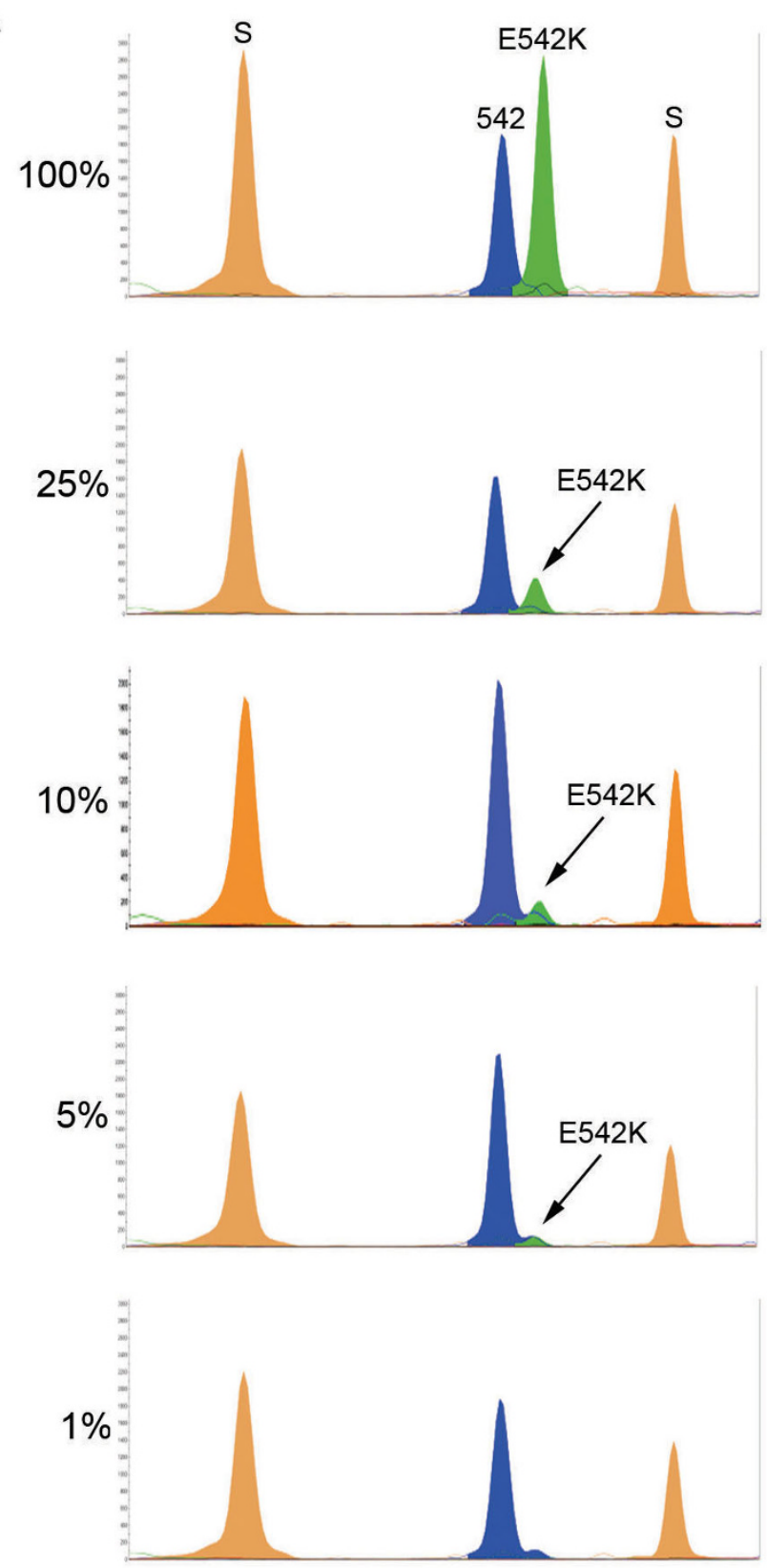

B
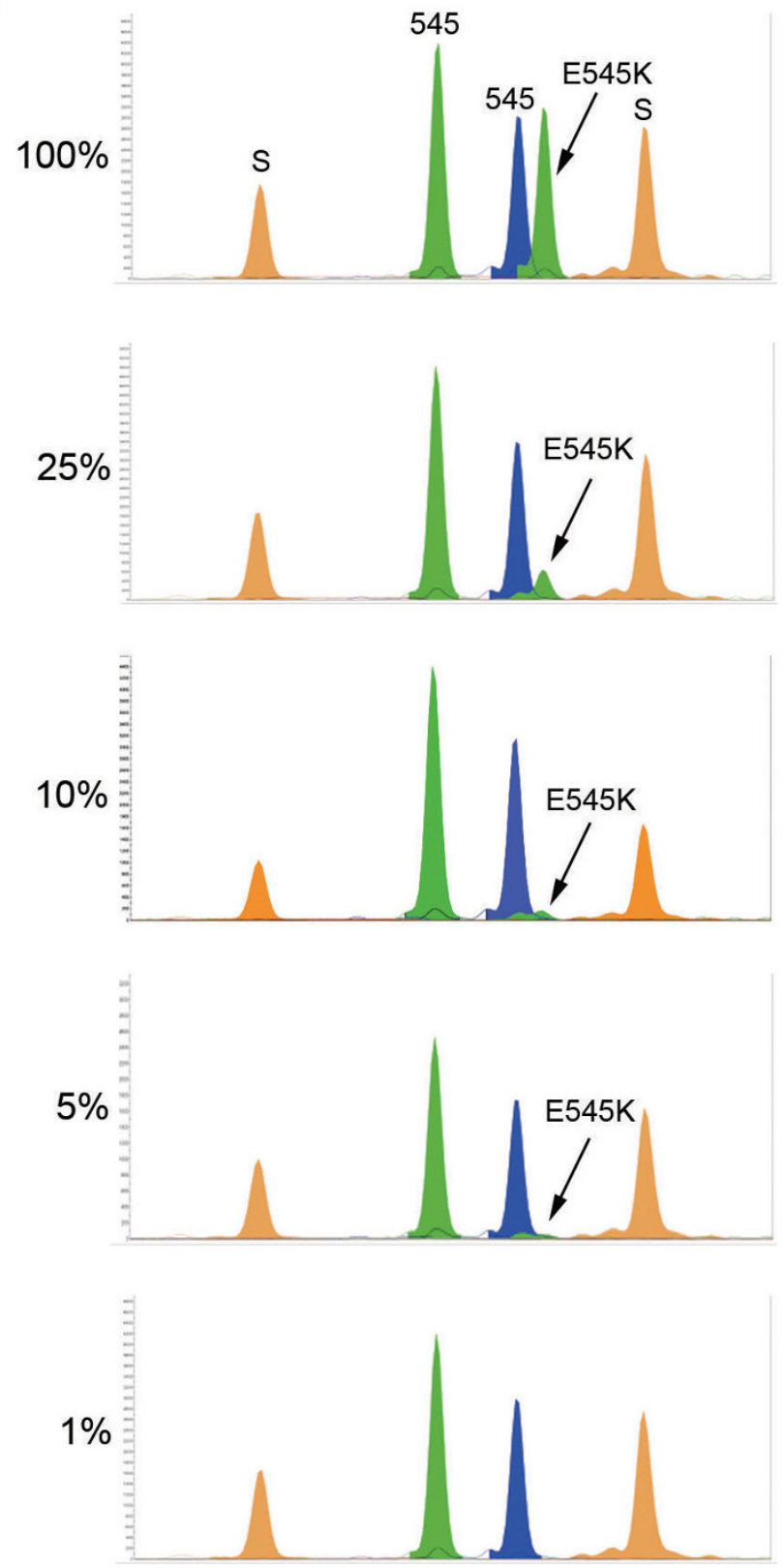

\section{Figure 2}

Sensitivity of the PIK3CA SNaPshot assay. SNaPshot could detect mutant PIK3CA when it represented $5 \%$ to $10 \%$ of the total DNA present. Representative examples for bladder tumors with (A) E542K and (B) E545K are shown.

Ready Reaction Mix is $£ 1.16$ per sample. In comparison a standard sequencing reaction using BigDye Terminator v1.1 Ready Reaction Mix costs $£ 2.59$ per sample. Methods that employ pre-screening approaches may initially represent a cheaper alternative to mutation detection but the subsequent requirement for sequence verification of potential mutations significantly increases the time and cost of these assays relative to the SNaPshot method. The PIK3CA SNaPshot assay is less expensive than methods which employ the use of fluorescently-labelled oligonucleotide probes [15] as the probes used in the SNaPshot assay are unlabelled primers. Pati et al. [20] compared the SNaPshot method to pyrosequencing and biplex invader SNP genotyping methods. The authors concluded that the 
SNaPshot assay required little optimisation and was comparable to these two methods but with a higher cost when singleplex reactions were used. The authors also reported that failed reactions were mostly associated with poor PCR amplification. In the present study, we have designed a robust multiplex PCR and did not observe any such reaction failures. The combined multiplex PCR and SNaPshot reaction makes it possible to screen simultaneously for four mutations. In addition, all steps of the SNaPshot assay are performed in 96 well plates and the method could easily be automated for high throughput analysis.

\section{Conclusion}

A SNaPshot assay for the simultaneous screening of four frequent PIK3CA codon mutations has been developed. The detection of multiple mutations in a single reaction reduces cost, amount of patient sample DNA and sample handling required. The interpretation of results is quick and easy and the method is flexible so that if required, appropriately sized probes targeting additional hotspot codons could be added to the assay. A major advantage is the avoidance of an extra sequencing step that is a requirement of many pre-screening-based methods.

As specific inhibitors for PIK3CA become available, rapid screening of patient samples for mutations will be essential. The SNaPshot assay described here can be high throughput and is robust and objective making it suitable for use in such a diagnostic setting.

\section{Competing interests}

The authors declare that they have no competing interests.

\section{Authors' contributions}

$\mathrm{CDH}, \mathrm{TZ}, \mathrm{EZ}, \mathrm{CH}$ and $\mathrm{MK}$ participated in the conception and design of the study, and writing of the manuscript. $\mathrm{CDH}$ and $\mathrm{CH}$ performed SNaPshot experiments and data analysis. All authors read and approved the final manuscript.

\section{Acknowledgements}

This work was supported by Cancer Research UK grant number C6228/ A5433. Christian Hafner was supported by the DDG/ADF Research Grant 2007 and by the ReForM-B grant of the University of Regensburg.

\section{References}

I. Vivanco I, Sawyers CL: The phosphatidylinositol 3-Kinase AKT pathway in human cancer. Nat Rev Cancer 2002, 2:489-50I.

2. Philp AJ, Campbell IG, Leet C, Vincan E, Rockman SP, Whitehead RH, Thomas RJ, Phillips WA: The phosphatidylinositol 3'-kinase p85alpha gene is an oncogene in human ovarian and colon tumors. Cancer Res 2001, 6 1:7426-7429.

3. Campbell IG, Russell SE, Choong DY, Montgomery KG, Ciavarella ML, Hooi CS, Cristiano BE, Pearson RB, Phillips WA: Mutation of the PIK3CA gene in ovarian and breast cancer. Cancer Res 2004, 64:7678-768I.

4. Hartmann C, Bartels G, Gehlhaar C, Holtkamp N, von Deimling A: PIK3CA mutations in glioblastoma multiforme. Acta Neuropathol 2005, 109:639-642.
5. Lee JW, Soung YH, Kim SY, Lee HW, Park WS, Nam SW, Kim SH, Lee JY, Yoo NJ, Lee SH: PIK3CA gene is frequently mutated in breast carcinomas and hepatocellular carcinomas. Oncogene 2005, 24:|477-| 480.

6. Levine DA, Bogomolniy F, Yee CJ, Lash A, Barakat RR, Borgen PI, Boyd J: Frequent mutation of the PIK3CA gene in ovarian and breast cancers. Clin Cancer Res 2005, I I:2875-2878.

7. Li VS, Wong CW, Chan TL, Chan AS, Zhao W, Chu KM, So S, Chen $X$, Yuen ST, Leung SY: Mutations of PIK3CA in gastric adenocarcinoma. BMC Cancer 2005, 5:29.

8. Saal LH, Holm K, Maurer M, Memeo L, Su T, Wang X, Yu JS, Malmstrom PO, Mansukhani M, Enoksson J, et al.: PIK3CA mutations correlate with hormone receptors, node metastasis, and ERBB2, and are mutually exclusive with PTEN loss in human breast carcinoma. Cancer Res 2005, 65:2554-2559.

9. Wang Y, Helland A, Holm R, Kristensen GB, Borresen-Dale AL: PIK3CA mutations in advanced ovarian carcinomas. Hum Mutat 2005, 25:322.

10. Wu G, Xing M, Mambo E, Huang X, Liu J, Guo Z, Chatterjee A, Goldenberg D, Gollin SM, Sukumar S, et al.: Somatic mutation and gain of copy number of PIK3CA in human breast cancer. Breast Cancer Res 2005, 7:R609-6I6.

II. Lopez-Knowles E, Hernandez S, Malats N, Kogevinas M, Lloreta J, Carrato A, Tardon A, Serra C, Real FX: PIK3CA mutations are an early genetic alteration associated with FGFR3 mutations in superficial papillary bladder tumors. Cancer Res 2006, 66:7401-7404.

12. Qiu W, Schonleben F, Li X, Ho DJ, Close LG, Manolidis S, Bennett BP, Su GH: PIK3CA mutations in head and neck squamous cell carcinoma. Clin Cancer Res 2006, I 2: I44 I- I 446.

13. Qiu W, Tong GX, Manolidis S, Close LG, Assaad AM, Su GH: Novel mutant-enriched sequencing identified high frequency of PIK3CA mutations in pharyngeal cancer. Int J Cancer 2008, I 22: I I89-II94.

14. Hafner C, Lopez-Knowles E, Luis NM, Toll A, Baselga E, FernandezCasado A, Hernandez S, Ribe A, Mentzel T, Stoehr R, et al.: Oncogenic PIK3CA mutations occur in epidermal nevi and seborrheic keratoses with a characteristic mutation pattern. Proc Natl Acad Sci USA 2007, I 04: 13450-13454.

15. Board RE, Thelwell NJ, Ravetto PF, Little S, Ranson M, Dive C, Hughes $A$, Whitcombe $D$ : Multiplexed assays for detection of mutations in PIK3CA. Clin Chem 2008, 54:757-760.

16. Simi L, Pratesi N, Vignoli M, Sestini R, Cianchi F, Valanzano R, Nobili $S$, Mini E, Pazzagli M, Orlando C: High-resolution melting analysis for rapid detection of KRAS, BRAF, and PIK3CA gene mutations in colorectal cancer. Am J Clin Pathol 2008, I 30:247-253.

17. van Oers JM, Lurkin I, van Exsel AJ, Nijsen Y, van Rhijn BW, Aa MN van der, Zwarthoff EC: A simple and fast method for the simultaneous detection of nine fibroblast growth factor receptor 3 mutations in bladder cancer and voided urine. Clin Cancer Res 2005, I I:7743-7748.

18. Filippini S, Blanco A, Fernandez-Marmiesse A, Alvarez-Iglesias V, RuizPonte C, Carracedo A, Vega A: Multiplex SNaPshot for detection of BRCAI/2 common mutations in Spanish and Spanish related breast/ovarian cancer families. BMC Med Genet 2007, 8:40.

19. Hafner C, Vogt T, Landthaler M, Musebeck J: Somatic FGFR3 and PIK3CA mutations are present in familial seborrhoeic keratoses. Br J Dermatol 2008, I 59:2 I4-2I7.

20. Pati N, Schowinsky V, Kokanovic O, Magnuson V, Ghosh S: A comparison between SNaPshot, pyrosequencing, and biplex invader SNP genotyping methods: accuracy, cost, and throughput. J Biochem Biophys Methods 2004, 60: I- I2. 